\title{
LEGAL ASPECTS OF DIRECT-TO-CONSUMER GENETIC TESTS
}

\author{
M. Yaneva - Deliverska \\ Institute for legal sciences, Bulgarian academy of sciences
}

\section{SUMMARY:}

Genetic testing is a type of medical test that identifies changes in chromosomes, genes, or proteins. Most of the time, testing is used to find changes that are associated with inherited disorders. The results of a genetic test can confirm or rule out a suspected genetic condition or help determine a person's chance of developing or passing on a genetic disorder.

The main difference between direct-to-consumer genetic testing and the standard genetic testing is the way informational support is provided in internet offers of testing. Counselling may be offered as an additional special service at extra costs and at the customer's request. It may also be that a recommendation or at least an offer is given for the customer to contact a doctor or health practitioner from the company via phone for counselling.

In a liberal society the fundamental individual rights can be considered to include access to medical treatment and diagnostics that may be helpful for improving one's health condition or that can help an individual make decisions regarding life style and health.

At the European level, there are no binding legal regulations that specifically apply for genetic testing. In some European counties, national laws, require a responsible medical person to be involved before a genetic test is provided.

The Convention on Human Rights and Biomedicine was adopted by the Committee of Ministers on 19 November 1996, while an Additional Protocol to the Convention, concerning Genetic Testing for Health Purposes, was adopted by the Committee of Ministers on 7 May 2008.

Direct-to-consumer genetic testing is closely watched by the community of medical genetics and counsellors, and the EU funded Eurogentest Network of Excellence.

In 2010, the European Society of Human Genetics has releaseda statement on direct-to-consumer gene testing for health-related purposes. The European Society of Human Genetics is concerned about the way in which commercial companies are currently introducing genetic tests into the market outside of the scope of the traditional healthcare system.

Key words: genetic condition, genetic testing, preventive medicine, legal regulations.
Traditionally, genetic tests have been available only through healthcare providers such as physicians, nurse practitioners, and genetic counselors. Healthcare providers order the appropriate test from a laboratory, collect and send the samples, and interpret the test results. Direct-toconsumer genetic testing refers to genetic tests that are marketed directly to consumers via television, print advertisements, or the Internet. This form of testing, which is also known as at-home genetic testing, provides access to a person's genetic information without necessarily involving a doctor or insurance company in the process.

The classical model of genetic counselling is meant to be a particular service for a particular segment of the population to whom diagnostics and advice was supplied with regard to a single genetic condition for which the patient has (due to family history or symptoms) reason to believe he is a carrier. Due to new technical developments it is today at least conceivable that a family doctor could offer routine testing for a series of genetic disorders that are associated with common diseases such as cancer, diabetes and heart disease.

Genetic testing is on its way to becoming an option for preventive medicine in general. It is discussed as a new important public health option, and the perspectives of pharmacogenetics and nutrigenomics make new attractive markets become visible. These perspectives meet with a general trend (both in the public's perception as well as in health care policy making) to give emphasis to individual prevention of disease by living up to certain lifestyle recommendations as well as by making use of diagnostic monitoring of one's health status. It can thus be expected that a bigger part of the general population will be inclined to make use of genetic testing services (even if the costs are not covered by the public health service or by health insurance).

Genetic testing is a type of medical test that identifies changes in chromosomes, genes, or proteins. Most of the time, testing is used to find changes that are associated with inherited disorders. The results of a genetic test can confirm or rule out a suspected genetic condition or help determine a person's chance of developing or passing on a genetic disorder.

Genetic tests are used for several reasons, including:

- carrier screening, which involves identifying 
unaffected individuals who carry one copy of a gene for a disease that requires two copies for the disease to be expressed

- preimplantation genetic diagnosis

- prenatal diagnostic testing

- newborn screening

- presymptomatic testing for predicting adult-onset disorders such as Huntington's disease

- presymptomatic testing for estimating the risk of developing adult-onset cancers and Alzheimer's disease

- confirmational diagnosis of a symptomatic individual forensic/identity testing

The main difference between direct-to-consumer genetic testing and the standard genetic testing is the way informational support is provided in internet offers of testing. Counselling may be offered as an additional special service at extra costs and at the customer's request. It may also be that a recommendation or at least an offer is given for the customer to contact a doctor or health practitioner from the company via phone for counselling.

In gene tests, scientists scan a patient's DNA sample for mutated sequences. A DNA sample can be obtained from any tissue, including blood. For some types of gene tests, researchers design short pieces of DNA called probes, whose sequences are complementary to the mutated sequences. These probes will seek their complement among the three billion base pairs of an individual's genome. If the mutated sequence is present in the patient's genome, the probe will bind to it and flag the mutation. Another type of DNA testing involves comparing the sequence of DNA bases in a patient's gene to a normal version of the gene.

The U.K. Human Genetics Commission defines directto-consumer genetic test as ".... any test to detect differences in DNA, genes or a chromosome that is not provided as part of a medical consultation." This includes any genetic test available to the public outside the usual medical control system. The Belgian Advisory Committee for Bio-Ethics uses the term "home-sampling test". A sample of the material to be tested is taken at home and sent to a laboratory for analysis. The results from the laboratory tests are communicated to the user by telephone, mail, e-mail or secured internet access. The definition includes a broad spectrum of tests, from ancestry testing, paternity determination and prenatal sex determination to heritable breast cancer testing.

In a liberal society the fundamental individual rights can be considered to include access to (and make one's own choice with regard to) medical treatment and diagnostics that may be helpful for improving one's health condition or that can help an individual make decisions regarding life style and health. Thus, a person has the right to make use of genetic testing just as of any other medical treatment or procedure. On the other hand, an individual may not be forced to seek genetic testing against his or her will. The principle of free choice and the possibly problematic character of information gained from genetic tests require that genetic testing may not be carried out without a person's explicit consent, i.e. that nobody should undergo a genetic test without his or her knowledge or against his or her explicit will. Whereas this principle in itself appears to be uncontested, it can be impeded by many factors.

Knowledge about one's own genetic condition must be regarded as an essential individual right, since this knowledge (in the case of predictive genetic testing) can inform important choices with regard to a person's future life. On the other hand, the character of genetic information may in some cases motivate a person to decide not to know about his own genetic condition, in order not to encumber his present life with the burden of the knowledge of the inevitable onset of a severe disease in the future. A right "not to know" is even more important since an individual's knowledge about his own genetic condition (and the possible future state of his health) in many cases implies knowledge about his relatives to be carriers of the very same genetic trait. It is therefore essential for the rights of relatives to be protected against unwilling disclosure of genetic information. In practice this may confront patients and doctors with a dilemma since they know about the genetic condition of relatives, yet do not have the possibility to decide whether these afflicted third persons want to know about the result or, on the contrary, would reject this opportunity to know about their own genetic status.

The principle of free choice and the frequently ethically sensitive character of the decisions to be made (e.g. in the case of abortion) necessitates that the client make his own decision and not be overruled by his doctor or genetic counsellor. As a result, professional associations have established the principle of non-directive counselling in their guidelines for counselling and genetic testing, which means that the counsellors part is to provide the best available information about the usefulness and possible consequences of a gene test to his patient, but not to lead him to a decision for or against the test, leaving this decision totally up to the patient himself.

With regard to genetic testing carried out for health purposes and tests that have important implications for the person concerned or family members, it is required that the test be performed under individualised medical supervision by a doctor.

At the European level, there are no binding legal regulations that specifically apply for genetic testing. In some European counties, national laws, require a responsible medical person to be involved before a genetic test is provided.

Austria and Switzerland have a specific genetic testing law dealing with and regulating some ethical and legal questions associated with genetic testing. In most countries, this issue has been regulated in existing 
professional guidelines for genetic testing and counselling. In 1991, in its Recommendation 1160, the Council of Europe Parliamentary Assembly recommended that the Committee of Ministers "envisage a framework convention comprising a main text with general principles and additional protocols on specific aspects."

The Convention on Human Rights and Biomedicine was adopted by the Committee of Ministers on 19 November 1996. The same year, the Committee of Ministers instructed the Steering Committee on Bioethics (CDBI) "to draw up a Protocol to the Convention on Human Rights and Biomedicine concerning the problems relating to human genetics..." and accordingly invited the CDBI “...to start work on it as soon as possible, taking also into account questions relating to the use and protection of the results of predictive genetic tests for purposes other than health or scientific research linked to health."

In June 1997, the CDBI appointed Dr Stefan Winter, Chairman of the Working Party on Human Genetics. A workshop on "Medical, ethical and social aspects of new and perspective developments in genetic research" was then held on 21 - 22 April 1998 in Leuven (Belgium), as well as a hearing of European patient organisations on 8 June 1998 in Strasbourg. On the basis in particular of the conclusions of those different meetings to start its work, the Working Party held its first meeting in September 1998.

The CDBI decided, at its 30th meeting (2-5 May 2006), to split the Protocol and to bring out separate instruments dealing with genetic testing for health purposes and genetic testing for employment and insurance purposes.

The Protocol was approved by the CDBI at its $32 \mathrm{nd}$ meeting (4-8 June 2007). The Parliamentary Assembly gave the opinion No. 267 (2008) on the Protocol, on 24 January 2008. The Protocol was adopted by the Committee of Ministers on 7 May 2008.

The Protocol applies to tests, which are carried out for health purposes, involving analysis of biological samples of human origin and aiming specifically to identify the genetic characteristics of a person which are inherited or acquired during early prenatal development.

This Protocol does not apply to genetic tests carried out on the human embryo or foetus; and to genetic tests carried out for research purposes.

According to article 7 of the Protocol, a genetic test for health purposes may only be performed under individualised medical supervision.

Regarding the direct marketing of genetic tests to the public, the Council of Europe considered that those tests may induce false needs, create undue expectations and bypass the need for medical indication, and, thus, jeopardises the right to genetic counselling and information for patients and the general public, and overloads the health system.
When non-medical applications of genetic tests are directly marketed to the public, transparency, fair advertising and quality assurance should also be required.

Health-related genetic tests for diagnostic or predictive purposes should not be made available for direct marketing to the public, in respect for the fundamental ethical principles.

In the U.S., the Federal Trade Commission together with the Food and Drug Administration and the Centres of Disease Control in July 2006 released a consumer alert because of the lack of scientific validity in some gene tests offered. Among U.S. authorities there seems to be serious concern that direct-to-consumer genetic testing may escape from proper quality control and oversight. In Europe, directto-consumer-genetic testing has been constantly observed and discussed avidly in the U.K., due to the initiative taken by the Human Genetics Commission.

Direct-to-consumer genetic testing is closely watched by the community of medical genetics and counsellors, and the EU funded Eurogentest Network of Excellence. In 2008, the German Society of Human Genetics in an official opinion judged direct-to-consumer offers for SNP testing as scientifically unsound and highlighted that genetic diagnostics in each case should be based on a profound medical consultation.

In 2010, the European Society of Human Genetics has releaseda statement on direct-to-consumer gene testing for health-related purposes. The European Society of Human Genetics is concerned about the way in which commercial companies are currently introducing genetic tests into the market outside of the scope of the traditional healthcare system. The released statement highlights the importance of right to information, quality of the test performed, clinical usefulness of the tests provided, the need for individualized medical supervision, the provision of pre-test information and genetic counselling, follow-up and support in the interpretation of results and their psychosocial impact, the protection of persons not able to consent, respect for privacy and confidentiality, and the storing of the samples, their property and respect for ethical principles in research.

Direct-to-consumer testing challenges many of the practices that have been developed around genetic testing and highlights the gaps in the regulatory regimes when applied to commercial testing of this kind. One of the significant challenges of direct-to-consumer testing is that it shifts the control of genetic testing from the clinical domain and medical professionals into the hands of consumers. No longer is genetic testing being carried out solely for medical reasons, by specialists in clinical genetics. This shift in control from the medical profession has caused consternation, but may force a re-evaluation of the way genetic testing is currently carried out and in the long term lead to better services driven by consumer needs. 


\section{REFERENCES:}

1. Magnus, D., Cho MK, Cook-Deegan $\mathrm{R}$, Direct-to-consumer genetic tests: beyond medical regulation?, Genome Med. 2009 Feb 2;1(2):17. [PubMed] [CrossRef doi: $10.1186 / \mathrm{gm} 17]$

2. Analysis of privacy policies and practices of direct-to-consumer genetic testing companies: Private sector databanks and privacy norms, Health Law Institute, University of Alberta, March 2010.

3. Hogarth S, Javitt G, Melzer D. The current landscape for direct-to-consumer genetic testing: legal, ethic, and policy issues, Annu. Rev. Genom. Human Genet. 2008.9:161-182. [ PubMed] [CrossRef do i : 10.1146 / a n nurev.genom. 9.081307.164319]

4. Kaye, J., The regulation of direct-toconsumer genetic tests, Human Molecular Genetics, 2008 Oct 15;17(R2):R180-R183. [PubMed] [CrossRef doi:10.1093/hmg/ ddn253]
5. European Parliament, Directorate General for internal policies, Direct to consumer genetic testion study, November 2008.

6. European Society of Human Genetics, Statement of the ESHG on direct-to-consumer genetic testing for health-related purposes, Eur J Hum Genet. 2010 Dec;18(12):1271-1273; Epub 2010 Aug 25 [PubMed] [CrossRef doi:10.1038/ ejhg.2010.129]
Address for correspondence: Mariela Yaneva - Deliverska mob: +359887574973

e-mail: yanevamariela@yahoo.com 